\title{
Comunicação e educação: algumas considerações sociológicas*
}

\section{RESUMO}

Os vínculos entre educação e comunicação são muitos. Proponho apresentar três deles extraídos da literatura sociológica francesa. A comunicação aparece como convidada da sociologia da educação: a) quando a sociologia da educação estuda a comunicação pedagógica entre o professor e os seus alunos e, de modo mais amplo, quando examina as interações entre os diversos atores na sala de aula; b) quando estuda as consequências na organização escolar da forte influência da mídia na sociedade contemporânea e aborda o papel na educação das novas tecnologias da informação e da comunicação; c) enfim, quando estuda a violência escolar pela qual a televisão é frequentemente considerada responsável, do que, em função da sua carga emocional, a mídia não consegue dar conta.

\section{PALAVRAS-CHAVE}

comunicação

educação

sociologia

\section{ABSTRACT}

The links between education and communication are many. I propose to present three of them taken from the French sociological literature. The communication appears as a guest of the sociology of education: a) when the sociology of education studies educational communication between teacher and students and, more broadly, when considering the interactions between different actors in the classroom, $b$ ) when studying the impact on school organization of influence of mass media in contemporary society and explores the role in the education of new information technologies and communication; c) finally, when studying school violence in which television is often held responsible, than depending on their emotional charge, the media can not cope.

\section{KEY WORDS}

communication

education

sociology

\section{Jean-Paul Laurens}

Professor da Université Paul-Valéry, Montpellier III/Paris/FR

jeanpaul.laurens@univ-montp3.fr
“Um educador é sempre um comunicador: toda educação implica uma comunicação, uma troca, uma relação intersubjetiva", escreve Louis Porcher, em Les médias entre éducation et communication (2009, p. 9). Daí o interesse da sociologia pela comunicação na sala de aula. Pode-se ilustrar esse primeiro ponto lembrando três linhas de pesquisa mais ou menos distantes no tempo.

\section{Comunicação e pedagogia escolar}

Em Les héritiers: les étudiants et la culture, Pierre Bourdieu e Jean-Claude Passeron (1966) abordam a questão da comunicação pedagógica tentando medir o seu impacto. Contrariando a ideia corrente sobre a ação do professor, eles concluem que a comunicação pedagógica é pouco eficaz. Em outras palavras, a relação entre transmissão de informações e tempo passado pelo estudante ouvindo o professor é deficiente. Muito tempo para pouca informação. A educação não alcança, em parte ou totalmente, o seu objetivo de passar o máximo de conhecimentos de uma geração para outra. Essa observação, encoberta pelo status, pelo prestígio, pela legitimidade e pelo carisma do professor, assim como, às vezes, pela teatralização da ação pedagógica, levou os sociólogos da educação dos anos 60 a apontar a verdadeira função da escola: a cooptação social e a reprodução em lugar da seleção pelo mérito e a transmissão dos saberes.

A análise feita por Pierre Bourdieu e Jean-Claude Passeron denuncia na comunicação pedagógica entre professor e aluno a geração de mal-entendidos e de subentendidos. Alguns exemplos:

O professor faz de conta que os alunos possuem os pré-requisitos para a compreensão da sua aula. Prova disso é o uso constante da expressão "como vocês sabem [...]", o que libera o professor de certos detalhes e permite-lhe avançar no conteúdo. Mas, ao dizer isso, ele fixa o que deve ser aprendido pelo aluno e torna incongruente a questão do estudante que não está compreendendo. Ora, observam Pierre Bourdieu e Jean-Claude Passeron, os conhecimentos que supostamente deveriam ser assimilados pelo aluno estão muitas vezes fora do programa, mas isso o aluno não está em condições de dizer seja para não se expor a comentários humilhantes do professor, cuja aula ele está atrapalhando, seja para não cair no ridículo junto aos seus colegas, que fingem compreender a mensagem do mestre. Poucos estudantes ousam pedir ao professor que explicite o implícito, ou seja, que fale claro para todos e não apenas para aqueles capazes de entendê-lo por terem aprendido o conteúdo em outras 
circunstâncias, fora da relação pedagógica.

Nessa mesma linha, pode-se falar da crítica constante aos estudantes por fazerem "trabalhos muito escolares", limitando-se a repetir o que foi dado. Ora, os estudantes que podem ir além disso são justamente aqueles que não dependem da escola para aprender, isto é, os oriundos de meios socioculturais favorecidos com acesso fácil aos bens culturais que contribuem para a distinção.

Em suma, Pierre Bourdieu e Jean-Claude Passeron tratam da situação pedagógica como uma comunicação de fraco rendimento destinada a alguns alunos apenas numa relação de conivência com o professor por razões mais socioculturais que escolares, mais herdadas do que por mérito.

\section{Comunicação e desempenho escolar}

Nos anos 1980, a sociologia da educação debruçouse sobre as interações escolares nas salas de aula. A partir daí, Régine Sirota (1988) observou que uma aula pode, num determinado momento, dividir-se em duas redes de comunicação:

Por um lado, uma rede principal, englobando uma parte da turma, na qual os alunos são atores da comunicação pedagógica, ou seja, participam, mostram interesse e dão sentido à situação pedagógica; por outro lado, uma rede de comunicação paralela, englobando o restante da turma, na qual os alunos desenvolvem comportamentos inadequados ou se tornam apáticos.

Essas duas redes de comunicação separam bons e maus alunos, aqueles que participam da relação pedagógica (fazem perguntas) e aqueles que se desinteressam (falam sem parar entre eles ou saem do ar). A origem social dos alunos aparece claramente no uso da palavra na rede principal de comunicação. $\mathrm{O}$ recuo caracteriza as crianças vindas das classes populares, enquanto o voluntarismo marca meninos e meninas das classes médias. O comportamento dos alunos vindos das classes médias altas é ambivalente, associando participação e desinteresse. Quando o bom desempenho escolar não é regra no grupo social de pertencimento, o comportamento dos bons alunos não é o mesmo dos colegas. Enquanto os bons alunos vindos das camadas baixas ou médias da classe média desenvolvem um "conformismo passivo", os filhos de operários com bom desempenho praticam um "conformismo ativo".

O comportamento do aluno tem relação direta com o seu desempenho escolar. É que o confirmam as pesquisas de Georges Felouzis (1994), que comparam quatro dimensões (participação, concentração, apatia e bagunça) com o objetivo de verificar se o melhor uso da comunicação pedagógica na sala de aula pelas meninas não explicaria o melhor desempenho escolar delas. Três observações:

Levantar a mão para ser questionado, pedir ao professor que veja o trabalho (demanda de avaliação), fazer perguntas ou responder, nada disso estabelece diferenças entre meninos e meninas. Em outras palavras, o jogo da competição escolar não obedece a diferenças de sexo.

Em contrapartida, as meninas investem mais do que os meninos em exercícios que exigem mais cooperação e interação. Por exemplo, trabalhos em grupo. Mesmo permanecendo concentradas no trabalho individual (escrever, reler), elas sabem interagir quando necessário, ou seja, prestar atenção no que diz o professor (olhar, escutar) e nos colegas (olhar, escutar o colega que está sendo questionado). As meninas dominam melhor as regras de interação fixadas pelo professor.

Já os meninos apresentam uma tendência para a agitação individual (conversar, gesticular, rir), assim como para a bagunça coletiva (brigas, empurrões, mudanças de lugar). Menos constantes no cumprimento das tarefas escolares ou em ouvir o professor, respeitam menos a situação pedagógica coletiva e interativa fixada pelo professor. Aproveitam menos a relação pedagógica.

\section{Comunicação e cotidiano escolar}

Para complementar este item sobre interações na sala de aula, podem-se citar as reflexões de Philippe Perrenoud (1998) sobre a realidade cotidiana da comunicação pedagógica. Ele chama a nossa atenção para algumas contradições, dilemas e ambiguidades interessantes de observar:

O tempo escolar é fracionado e cronometrado. Adapta-se mal ao tempo morto e ao silêncio indispensável à reflexão. Muitas vezes, o aluno nada tem a dizer quando é convocado a falar. O professor precisa aceitar isso se deseja que o aluno se torne comunicativo.

As pedagogias mais ativas baseadas na interatividade da relação pedagógica não deixam de estressar alguns alunos obrigados a falar mais do que desejariam. Essa situação pode acarretar um bloqueio contraproducente em termos de interação escolar.

São quase sempre os mesmos alunos que fazem uso da palavra na sala de aula e não necessariamente aqueles para os quais a palavra seria mais útil pedagogicamente. Muitos estudantes não ousam falar, embora isso pudesse ser extremamente benéfico para eles.

Sabendo da tendência natural à comunicação apenas com os alunos que valorizam os ensinamentos, o professor deve ter o cuidado de estabelecer um equilíbrio na distribuição e no uso da palavra em sala de aula.

$\mathrm{Na}$ sala de aula, o aluno experimenta uma grande exposição. Está permanentemente sob o olhar dos outros. Assim, a escola é uma instituição "panóptica" onde para saber alguma coisa, obter ou comunicar uma informação é, às vezes, inútil falar: basta olhar. 
Num espaço tão restrito e indiscreto quanto a sala de aula (onde se vê tudo e tudo se sabe), é preciso permitir que o aluno se esconda um pouco (até mesmo mentindo) para não perder a face em público. Isso lhe permite preservar sua autoestima, o que é muito importante para o bom desempenho na escola.

A comunicação escolar é, muitas vezes, violenta e humilhante. Por exemplo, quando faz com que um aluno tenha de falar em sala de aula sobre uma questão íntima ou quando obriga um aluno a dizer publicamente que ele não sabe ou, ainda, quando estimula o conflito ou a polêmica.

$\mathrm{O}$ olhar dos outros leva, muitas vezes, à prudência e à autocensura na comunicação escolar. De fato, os alunos mostram discernimento quanto ao que se pode dizer ou não na escola. Aprendem rapidamente a não se abrir e a não dar aos outras armas com as quais ser atacado.

$\mathrm{Na}$ mesma linha, pode-se observar que quando o professor faz uma pergunta a maioria dos alunos evita responder, mesmo sabendo a resposta ou tendo algo a dizer.

Philippe Perrenoud refere-se ao tempo passado sem nada dizer ou fazer além de escutar o professor. Para suportar tal situação, o aluno desenvolve uma estratégia de comunicação clandestina feita de tagarelice, de mensagens, de gestos, de piscadelas[...] A interação escolar assume, às vezes, a forma de catarse : revolta prudente, raiva contida, humor áspero[...]

A escola põe em comunicação alunos oriundos de tradições culturais diferentes que nem sempre compartilham os mesmos códigos de expressão e de comunicação. Alguns alunos não respeitam as normas de expressão acadêmicas entre colegas. Deve-se deixar que continuem assim ou corrigir-lhes o estilo sob pena de bloquear-lhes o esforço de expressão e participação?

$\mathrm{Na}$ instituição escolar, a comunicação carrega o peso do respeito ao saber e à verdade. Existe uma autoridade, a do "professor que sempre tem razão", que tem o conhecimento, que julga e avalia quanto à forma e ao conteúdo as opiniões emitidas. $O$ condutor do jogo não pode, porém, esquecer que o erro é formador.

Na escola, enfim, nem sempre a comunicação está voltada para a aprendizagem. Ela serve, às vezes, para alguém se exibir, pedir elogios ou, ainda, alcançar uma posição de influência no grupo.

\section{Mídia, escolarização e educação na França}

A problemática da comunicação é abordada pela sociologia da educação quando esta estuda a influência da mídia na sociedade e as mudanças resultantes disso no universo escolar. Foi nos anos 1960 que apareceram os primeiros textos em francês sobre esse assunto. Pode-se ilustrar esse segundo ponto citando Georges Friedmann e, claro, McLuhan, mas também algumas reflexões contemporâneas sobre a educação e as novas tecnologias da informação e da comunicação no sistema educativo francês.

\section{A escola e a cultura de massa}

Georges Friedmann é mais conhecido na França por suas pesquisas no campo da sociologia do trabalho do que por seus escritos sobre a interface escola/mídia. No entanto ele publicou sobre o assunto, no começo dos anos 1960, vários textos nos primeiros números da revista Communication $(1961 ; 1963)$ e no jornal Le Monde (1966). Os seus objetivos podem ser resumidos em dez pontos:

A escola nunca teve o monopólio da educação das crianças. Essa função é compartilhada com a instituição religiosa e a família. Em certos casos, com a natureza (a escola da vida). Hoje, daria para falar em escola das ruas.

Desde os anos 1960, a escola oficial deve atuar junto com um novo parceiro no campo da educação dos jovens: os meios de comunicação de massa. Televisão, rádio, cinema e jornais, queira-se ou não, desempenham um papel de verdadeira "escola paralela" na socialização.

As imagens difundidas pela televisão rivalizam fortemente com as imagens dos manuais escolares, ainda mais que aparecem associadas ao lazer e ao prazer. Mas não é possível deixá-las de lado sem examiná-las. Os efeitos dos programas de televisão não se limitam ao divertimento e à passividade, pois eles informam e alimentam a capacidade humana de julgamento.

Georges Friedmann aponta alguns perigos na mídia. Se a televisão "infantiliza" o adulto, ela transforma as crianças em adultos "prematuros", afogando-os com informações das quais eles ainda não são capazes de separar a parte real da imaginária, o sério e o fútil, o universal e o particular. Veicula, além disso, saberes efêmeros, instáveis, desorganizados, superficiais, sedutores e até mesmo ilusórios.

Mas o grande perigo mencionado por Georges Fridmann é de se ver um dia essa escola paralela ser "voltada eficazmente" contra o "espírito crítico" e o "espírito cívico". Daí a sua tese: a escola não deve rejeitar as novas realidades provocadas pelo avanço das novas tecnologias da comunicação de massa. Fazer isso significaria "assinar a sua condenação" e deixar o campo livre para os usos nocivos dos novos meios. A escola, mais do que qualquer outra instituição, deve cuidar da educação do "consumidor" da mídia.

Para fazer isso a escola deve evoluir com o seu tempo. Se a primeira forma da escola voltou-se para homens dispensados de trabalhar, em seguida (pressionada pela revolução industrial) ela se orientou para a preparação do trabalhador. Enfim, chegou o tempo de ela se ocupar do "homem depois do trabalho", o tempo de ensiná-lo a selecionar, ordenar e interpretar a massa de informações recebidas, "dando aos jovens 
instrumentos de escolha".

Esse propósito exige dos professores que eles preparem os estudantes para o uso e o estudo dos programas de televisão a fim de que se tornem telespectadores críticos e exigentes, capazes de escolher e de criticar a "programação da noite". A instituição escolar deve, portanto, lutar contra o "analfabetismo visual”. Em síntese, para Goerges Friedmann,

Para se ter alguma chance de mudar as comunicações de massa no sentido de uma qualidade mais elevada, será preciso mexer com o público, em primeiro lugar os jovens por meio dos professores e da escola. Educar o consumidor de comunicação de massa é realizar uma condição necessária, nem sempre suficiente, para que a sociedade industrial seja formada por utilizadores de tecnologias, não por homens submetidos a elas (1966, p. 10)

Vale destacar que a resistência dos professores é muito grande para que se possa avançar nesse propósito. A televisão é percebida por eles de maneira essencialmente negativa. No entender deles, ela devora as noites e cansa os jovens. Estimula a passividade, a dispersão e a superficialidade. Desvaloriza o esforço. Faz com que os jovens assistam às aulas como se estivessem vendo televisão: afundam-se nas cadeiras, olham o espetáculo e recusam-se a qualquer participação. A televisão é percebida pelos professores como uma concorrente "desleal" tendo em seu favor o lazer, a facilidade e a modernidade, deixando para a escola o tédio, a dificuldade e a mesmice.

Georges Friedmann concluiu que a educação necessária para as novas gerações na cultura de massa passa, em primeiro lugar, pela formação dos educadores, ou seja, dos próprios professores.

Vale destacar que há no discurso dos professores uma influência das teses da Escola de Frankfurt, que estigmatiza a mídia de massa, focalizando criticamente os conteúdos ideológicos veiculados, e denuncia especialmente a alienação no capitalismo, a uniformização social e, ao final, o recuo da cultura erudita.

\section{Escola e mídia}

Na mesma época de Friedmann, do outro lado do Atlântico, Marshall McLuhan interpela a escola nas suas reflexões sobre a comunicação. Das várias obras de McLuhan traduzidas para o francês, é possível extrair os seguintes elementos:

Para Marshall McLuhan a evolução histórica das sociedades resulta do enriquecimento dos seus meios de comunicação segundo duas rupturas fundamentais. O estado tribal e oral da humanidade é primeiramente destruído pelo advento do alfabeto e da escrita, que possibilitam o exercício do poder sobre vastos impérios. Ao facilitar a reprodução e a circulação dos textos e das ideias, a possibilidade de imprimir provoca a democratização dos saberes e das sociedades. Facilita também o desenvolvimento cientifico, industrial e capitalista. Os professores, contudo, criticavam o livro sob alegação de que estimulava a preguiça e liberava do esforço de memorização. A invenção dos meios elétricos e eletrônicos, como o rádio, a televisão e o telefone, provocaram, em seguida, uma nova ruptura, transformando a relação entre espaço e tempo, prenúncio da globalização da atividade e do pensamento humanos. É a famosa aldeia global e planetária (McLuhan, 1970).

O impacto de um meio reside menos no que ele veicula do que naquilo que a sua tecnologia induz como mutação cultural profunda: "o meio é a mensagem". Segundo McLuhan, os meios de expressão da época da tecnologia elétrica dão uma forma e uma estrutura novas às interfaces sociais e um nova cara a cada elemento das experiências individuais, o que acarretaria uma revisão total do pensamento, das ações e das instituições vigentes. Nada ficaria intocado, nem a família de cada um, nem os vizinhos, nem a educação, nem o governo, nem o meio, nem as relações entre as pessoas. Enfim, nos termos dele, "uma mudança dramática (McLuhan, 1968). A cada meio, portanto, corresponde um mundo, uma cultura, uma geração, um pensamento, uma educação...

A passagem de um meio a outro, da galáxia Gutenberg (McLuhan, 1967) à galáxia Marconi, por exemplo, no século $\mathrm{XX}$, provoca um conflito de gerações: "Nosso ambiente eletrônico cavou um fosso entre as gerações", escreveu McLuhan. Segundo ele, nos pais continuaria predominando o hemisfério esquerdo, enquanto que os filhos teriam começado a fazer experiências sob a dominação do hemisfério direito (McLuhan, 1968). Essa situação não deixa de incidir sobre o processo educacional na medida em que a educação da nova geração se realiza por toda parte através da geração antiga. Na verdade, Marshall McLuhan associa mídia e geração.

De um lado estão os meios quentes (rádio, fotografia, texto, conferência) que por serem ricos em informações exigem pouco investimento da parte dos consumidores para dar sentido à mensagem. Próximos dos pais e da galáxia Gutenberg, desenvolvem o hemisfério esquerdo (o lógico e o linear), destribalizam a comunidade humana, produzem um homem fragmentado, solidariedade orgânica e favorecem a pesquisa em profundidade, mas limitada. Do outro lado estão os meios frios (telefone, histórias em quadrinho, televisão, a palavra) que, por serem pobres em informação, exigem muito investimento da parte dos consumidores para dar sentido às mensagens. Próximos dos filhos e da galáxia Marconi, desenvolvem o hemisfério direito (o simultâneo e o intuitivo), retribalizam a comunidade humana, produzem um homem integral, solidariedade mecânica e favorecem a investigação superficial, mas global. 
Na verdade, esse conflito geracional e mídiático se repete na escola e na sua pedagogia, que privilegia o escrito e o livro, situando-se incontestavelmente do lado dos meios "quentes", enquanto a juventude já é fortemente socializada nos meios "frios". Assim, quanto mais a criança estiver integrada aos novos meios, mais o sistema educativo lhe parecerá incongruente e irreal. Daí resulta esta crítica fortíssima de McLuhan à escola: em vez de ajudar os jovens a compreender a revolução em curso, o sistema educativo se comportaria como um instrumento de agressão cultural tentado impor a uma juventude neotribalizada um sistema de valores visuais anacrônico, produto de uma era alfabética moribunda.

Para McLuhan, essa situação era típica de um sistema educativo reacionário voltado para valores e tecnologias ultrapassados. Ele percebia, no entanto, que a velha geração acabaria por se entregar, pois o fosso entre as gerações havia se tornado profundo demais. Assim, considerava que o sistema educativo dominante, baseado na alfabetização e em dados fragmentados, era apenas um reflexo no retrovisor, um sistema "moribundo, ultrapassado", incapaz de corresponder às necessidades das novas gerações filhas da televisão. Era para ele, portanto, fácil compreender a agitação que fermentava nas escolas (McLuhan, 1977). McLuhan entendia que a criança da sua época crescia em meio a uma situação absurda, entre dois mundos e dois sistemas de valores, nenhum deles capaz de abrir caminho para a maturidade, gerando dificuldade para se chegar à idade adulta. Parecia-lhe necessário recorrer a um método global para sair da simples repetição de fatos e dados. De nada adiantaria, segundo sua metáfora, bancar o feiticeiro diante de problemas de uma usina nuclear. Ele perguntava se alguém acreditava de fato na possibilidade de fazer uma criança viciada nas tecnologias da era eletrônica reagir favoravelmente aos estímulos de um sistema de educação superado. Afirmava que crer nisso seria como esperar que uma águia começasse a nadar.

Quando um sistema não corresponde mais ao seu meio, dizia ele, torna-se incompreensível. Para uma criança da era da televisão, afirmava também, era quase impossível se adaptar aos objetivos fragmentados da educação visual dominante. $O$ problema estaria em tirar abruptamente a criança do "meio frio" da televisão para jogá-la no "meio quente" do impresso, sem contar a dificuldade da sua imersão num universo burocrático feito de aulas a acompanhar e de pontos a ganhar. Enquanto o instinto natural da criança, condicionado pelos meios elétricos, a levaria a absorver o conteúdo de um livro por meio de todos os seus sentidos, a leitura exige o contrário, o isolamento da vista em relação aos demais sentidos (McLuhan, 1977, p. 57-58).

Para Marshal McLuhan, enfim, as noções fundamentais de tempos e de espaço são diferentes no mundo eletrônico da era Marconi e no mundo escolar da era Gutenberg. Afinal, segundo ele, os meios eletrônicos recuperam o estágio oral e reduzem o tempo e o espaço (McLUHAN, 1977, p. 100). Já a escola remete o aluno para o tempo longo da escrita. McLuhan opõe, na verdade, de um lado a monocronia (na qual o ator produz cada coisa no seu tempo e uma coisa de cada vez), que implica sequencialidade, atenção prolongada, preparação e silêncio, e, de outro lado, a policronia (na qual o ator produz tudo ao mesmo tempo), que implica simultaneidade, tempo curto, instantâneo e ruído. Ele opõe a monocronia praticada na escola e pelos professores à policronia praticada na mídia e pelos jornalistas. Para Marshall McLuhan as tecnologias da informação e da comunicação transformam o espaço comprimindo-o até que ele se torne uma única e imensa aldeia global, acarretando, nos seus termos, um confronto no imediato (McLuhan, 1977, p. 130). Caberia, segundo ele, passar da escolha que isola como uma ilha à "escola planeta".

\section{Mídia e educação na França de hoje}

Georges Friedmann e Marshall McLuhan tiveram, na França, alguns seguidores. Louis Porcher e Fabrice Barthélémy, por exemplo, estudam o desenvolvimento da educação nas escolas contemporâneas. Surpreendentes nas pesquisas deles é a constatação de que pouca coisa mudou em meio século. As relações entre o mundo escolar e o mundo da mídia ainda se baseia num mal-entendido. A mídia interfere consideravelmente na educação e na socialização das novas gerações. Os pais, por exemplo, delegam à televisão a guarda dos filhos nas manhãs sem escola. Em contrapartida, a telinha forja e formata os jovens. No final, tanto os pais quanto os professores perdem o monopólio das informações e da educação.

Quando Louis Porcher (1994) compara escola e televisão nos anos 1990, constata que para os professores a televisão transmite conhecimentos inadequados por serem pontuais, incompletos, aleatórios, fragmentados, aproximativos, sem controle, superficiais e toscos. Assim, para os professores a televisão fragiliza a cultura cientifica e erudita e comete três pecados capitais: a violência, o sexo e a publicidade, que desviam a criança do bom caminho e a fazem crescer cedo demais. Se os professores estiverem certos, por causa da televisão, os jovens não leem mais, contestam tudo, negociam, estão sempre com pressa, cansam-se rapidamente, zapeiam sem parar, impacientam-se facilmente, acreditam em tudo e são afetivos, emocionais e utilitaristas.

Assim, 30 anos depois dos textos de Georges Friedmann e de Marshall McLuhan, o saber midiático continua ignorado pela instituição escolar: a televisão não tem moral, explora a credulidade, fatiga dos alunos, desenvolve a passividade, não é seletiva, baseia-se no prazer e dá maus exemplos à juventude. 
Em suma, a ruptura entre a escola e a televisão continua atual em parte pelo fato de que os professores se sentem concorrendo na missão de educar com um adversário desleal e ilegítimo que valoriza o prazer em vez de valorizar o trabalho e o esforço. Constatase também que a desafeição escolar pela mídia é correspondida. De fato, a televisão e os jornalistas não perdem oportunidade de, falando da escola, destacar os problemas: estrutura pesada e lentidão administrativa, abandono e fracasso escolar, jornadas longas e aborrecidas para os alunos, dificuldade de aceitação das novidades e passividade das equipes pedagógicas, monotonia no cotidiano escolar, professores desinteressantes, falta de atualidade, desinteresse, rigidez e passadismo[...]. Eis alguns aspectos negativos.

Dez anos depois, ou seja, no começo dos anos 2000, Fabrice Barthélémy (2001) fez as mesmas constatações: a educação pela mídia é aceita nas escolas em "doses homeopáticas". Daí decorre a existência de um fosso contraproducente para a sociedade entre a realidade escolar e realidade mídiática, embora seja cada vez maior o papel dessas duas instituições na cultura social. Enquanto os jornais disparam de bom grado contra os atrasos escolares, os professores atacam o sensacionalismo jornalístico. Continuamos em plena "exclusão recíproca", segundo a expressão de Michel Tardy (1966). Enquanto que nas salas de professores a mídia é menosprezada, nas salas de redação estigmatiza-se a cidadela impenetrável e o "mamute" escolar impossível de ser reformado.

Para Fabrice Barthélémy o mal-entendido escola/ mídia baseia-se em vários pontos. Primeiramente há o problema das representações sociais recíprocas de professores e jornalistas. Os professores têm uma visão maniqueísta da mídia (influência da sociologia crítica). Daí a resistência que opõem à introdução do "lobo-mídia" no "curral-escola". Mais do que isso, entendem que a televisão produz uma ilusão de ótica perigosa para alunos muito jovens, mais inclinados a engolir do que a mastigar. Por fim, associam a mídia a um quarto poder manipulador. $\mathrm{O}$ mal-entendido baseia-se também na suposta influência nefasta da televisão sobre as crianças. Os professores associam a telinha à violência no sentido de que a violência da televisão levaria as crianças à violência escolar, ao cansaço, na medida em que olhar televisão até tarde da noite explicaria o desinteresse na escola e a preguiça, à letargia, à facilidade e à passividade, portas para a alienação. Valores contrários ao espírito crítico cultivado pela escola. Enfim, professores e jornalistas desenvolvem, por exemplo, uma concepção essencialmente oposta do tempo escolar e do tempo midiático: tempo da reflexão versus tempo da emoção, lógica versus sensação, atualidade versus história, reação versus análise, curto versus longo, efêmero versus durável, obrigação versus liberdade, formação versus divertimento, esforço versus prazer, ativo versus passivo, criatividade versus passividade, cultura versus lazer... Para os professores o tempo da mídia é um tempo de submissão enquanto que para os jornalistas o tempo escolar é um tempo anacrônico.

Parafraseando Geneviève Jacquinot-Delaunay pode-se dizer que entre os "fanáticos do meio" e os "tecnófobos por princípio" existe espaço para um campo científico (2001, p. 293). A aproximação tranquila entre mídia e escola, no entanto, ainda não aconteceu.

\section{Mídia, escola e violência}

Para fechar estas considerações sociológicas sobre as relações entre educação e comunicação cabe abordar a questão da apropriação pela mídia da violência escolar a partir do exemplo francês, examinando casos da televisão, dos jornais e revistas e, enfim, dos sites de informação na internet. Existem sobre esse assunto pesquisas empíricas baseadas em análise de conteúdo.

\section{A violência escolar na televisão}

Mohammed Darmame (1999) estudou em torno de 60 reportagens exibidas nos telejornais das 20 horas nas seis principais redes de televisão da França em 1996. Uma rápida comparação com o ano de 1995 mostra que o número de reportagens sobre a violência escolar cresceu sete vezes mesmo se os fatos permaneceram estáveis. As notícias, portanto, estiveram descoladas da realidade. Em contrapartida, a maioria das reportagens focaliza escolas da periferia onde se concentra a violência cotidiana. Essa pesquisa revela sobretudo que a violência no meio escolar, como é descrita nos telejornais, não corresponde em parte ao que é vivido pelos atores sociais nem ao que é observado pelos pesquisadores.

Quando a televisão focaliza a violência escolar, aborda casos de violência e explicações institucionais, ou seja, punições e medidas preventivas. Cconcretamente a televisão se interessa antes de tudo pelos casos de violência (Darmame, 1999, p. 75). A diferença de enfoque de uma emissora para outra é grande. Os fatos em si representam $80 \%$ da cobertura de France 3 (televisão pública de tendência regional), Canal Plus (emissora privada a cabo) e M6 (emissora privada voltada para os jovens) e $50 \%$ da cobertura de TF1 e France 2 (as duas grandes redes nacionais, uma privada e outra pública). Nas emissoras públicas, políticos são chamados a opinar constantemente ( $1 / 3$ a $1 / 5$ do tempo), o que faz pensar que eles utilizam essas notícias em suas estratégias eleitorais. A análise das reportagens mostra também que a violência simbólica, a violência institucional e a violência econômica são subestimadas, pois as punições aos atos de violências não recebem grande atenção.

Enfim, quando a televisão aborda a violência escolar, dá espaço para fatos nem sempre relevantes, 
por exemplo uma briga diante da escola por razões alheias ao universo escolar. Em contrapartida, deixa de lado inúmeras questões de mau comportamento que fazem parte do cotidiano da violência escolar. Para Mohamed Darmame, a lógica da mídia, marcada pelo pouco tempo, acaba por privilegiar o foco naquilo que não está funcionando (Darmame, 1999, p. 85), ou seja, o aspecto penal das violências escolares, os incidentes graves, que são, na verdade, poucos numerosos.

\section{Violência escolar nos jornais e nas revistas}

As pesquisas empíricas quantitativas e qualitativas são ainda mais numerosas quando se trata da cobertura da violência escolar por jornais e revistas. Na verdade, repetem ou ampliam as observçõees relativas à televisão.

Um exemplo são as pesquisas de Benjamin Paty (2004), que comparam o conteúdo dos despachos da agência France Press com artigos publicados na imprensa e com estudos científicos sobre a questão da violência escolar. Essa pesquisa mostra primeiramente que os despachos são mais factuais e objetivos que os artigos, pois estes abrem espaços para análises e interpretações gerais. Uma prova disso está na escolha dos conectivos lógicos (conjunções coordenativas ou subordinativas) utilizados para ligar as ideias do discurso: os conectivos aditivos, mais objetivos, são claramente menos numerosos nos artigos que nos despachos, onde aparecem mais conectivos de comparação, oposição, disjunção e causalidade.

A pesquisarevela tambémumaausência decorrelação entre o número de artigos e o número de despachos produzidos. Seja ao longo de um ano escolar ou de um ano para outro, existem períodos em que os despachos não são seguidos pela publicação de artigos de análise e de reflexão sobre casos de violência escolar. Aparece também que, das cerca de 30 explicações existentes na literatura científica sobre a violência escolar, apenas 14 ganham espaço nos despachos, enquanto 23 aparecem nos artigos. Se estes recorrem a uma maior diversidade causal, hiperdimensionam a causa socioeconômica, enquanto os despachos privilegiam as causas culturais e psicológicas.

Pode-se também citar o estudo de caso de Nathalie Auger (2006), que compara o tratamento midiático pela imprensa local e nacional de um caso de violência escolar. O caso estudado é a agressão verbal e física de um professor por um aluno na saída da escola. $\mathrm{Na}$ sequência, um grupo de professores denuncia a falta de atitude do diretor e dá inicio a um movimento de greve de 15 dias. A cobertura de um jornal nacional considerado sério (Le Monde) possibilita as seguintes observações: o título destaca a rotina da violência escolar: "A violência se enraíza nas escolas".

A primeira frase da reportagem retoma a mesma ideia em tom interrogativo: "A violência tornouse parte da vida de certas instituições?" Por fim, o texto dá conta da estabilização dos casos de violência nas escolas francesas. Um intertítulo, "uma cultura institucional", dá a entender ao leitor apressado que uma cultura da violência se instalou nas escolas, embora o texto mostre a inexistência de tal cultura na medida em que há grande rotatividade de professores. Enfim, indica, a partir dos depoimentos dos alunos, uma predominância da violência urbana em relação à violência escolar. Já os especialistas apontam como causas da violência escolar a instabilidade das equipes de professores, a composição das turmas e uma aplicação inconstante das punições assim como a pouca atenção à violência oriunda da vida nos bairros. O título da reportagem dramatiza o conteúdo certamente para agarrar o leitor. O intertítulo é ambíguo, mas o conteúdo é serio e objetivo.

$\mathrm{Na}$ imprensa local, o mesmo acontecimento (12 textos no jornal Indépendant) suscita uma série de comentários. A abordagem local repercute a nacional retomando quatro pontos como causadores de violência escolar. Em primeiro lugar, a aplicação das punições. Os professores queixam-se da falta de atitude do diretor. Critica-se o facto de inexistirem regras escritas articulando as decisões e as punições. O problema da composição das turmas aparece nesta frase: "De tanto querer integrar todo mundo, desintegra-se o conjunto".

Na realidade, a imprensa local retoma a observação de um especialista e a inverte. Transforma a política da direção de apostar na heterogeneidade social nas turmas em causa do sofrimento e da violência escolar. Ao final, a imprensa local focaliza o diretor. Nathalie Auger observa: a abordagem do local do caso contradiz sistematicamente os argumentos do diretor, transformado em "bode-expiatório" da situação. Um artigo final, porém, faz a sua defesa, destacando que o mau aluno sempre acaba protegido, que a palavra raramente é dada aos estudantes, que o caso em questão era apenas o detonador de uma situação insustentável e que o diretor da escola se tornara vítima de uma violência insuportável e exagerada.

Publiquei na revista Famecos um texto sobre esse assunto $^{1}$. Quais eram as minhas conclusões? Primeiro que a violência escolar ganhava mais espaços de mídia em períodos de campanha eleitoral. A questão da segurança tornou-se nas últimas décadas um tema incontornável dos posicionamentos políticos no tabuleiro francês. A violência escolar deixou de ser um assunto tabu a ser resolvido internamente pelas escolas. A segunda constatação que fiz dizia que as notícias sobre a violência escolar hiperdimensionavam os casos de violência excepcional (por exemplo, uma tentativa de homicídio) em detrimento dos casos de violência comum e recorrente (por exemplo, atitudes de falta de educação). Eu havia tomado o exemplo de um jornal para adolescentes e comparado os títulos com as estatísticas nacionais da violência escolar. 
O ponto de vista distanciado dos especialistas era secundário em relação à narrativa, ao acontecimento e ao emocional.

\section{A violência escolar nos sites de informação}

Quatro anos mais tarde, retomei esses dois pontos na medida em que o primeiro semestre de 2009 ilustrava extraordinariamente as conclusões relativas ao primeiro semestre de 2005. Abordarei agora os dados de um site comunitário de informações gratuitas, Lepost.fr (pertencente ao grupo Le Monde), que existe desde o fim de 2007 e associa as informações clássicas da redação com informações em rede postadas por internautas que alimentam o site assim como por blogueiros, que opinam. Algumas observações:

A cobertura da violência escolar é mais ampla que a dos jornais nacionais. Uma centena de "posts" contra 35 textos no Monde, uns 50 no Libération, uns dez em La Croix ou no Figaro. A grande maioria dos "posts" descreve acontecimentos de violência escolar. Já os textos nos jornais abordam as questões de fundo, a dimensão política e o ponto de vista de especialistas.

Os casos de violência escolar descritos (em torno de 50) são, em contrapartida, graves e passíveis de punição judicial. Casos comuns de falta de educação ou outras incivilidades não recebem destaque. São casos como os de uma quinzena de alunos agressores de professores, guardas, diretores, usando facas, tesouras, gás, dando socos ou fazendo ameaças. Ou de ataques a colegas por uns 15 alunos com revólveres, lâminas, socos e pontapés, tesouras, chaves de fenda, insultos homofóbicos, agressões sexuais, etc. Ou das invasões a escolas por umas 12 pessoas para agredir professores ou alunos. Dois professores atacaram um aluno. Tudo isso coincide com os fatos graves levantados pelo Ministério da Educação em 2007 e 2008 (Laib, 2008). Alguns casos, contudo, não são propriamente de violência escolar. Por exemplo, uma briga de dois estudantes por uma menina numa parada do ônibus, um ataque a um menino no caminho da escola. Por outro lado, o noticiário de 2009 superestimou a violência praticada por invasores de escolas.

Sobre este último ponto, um caso teve um papel importante no noticiário de 2009. Foi a invasão, em 10 de março de 2009, de uma escola de ensino médio da periferia de Paris por um bando de 20 jovens armados de facas e de barras de ferro. Eles feriram e traumatizaram em torno de 15 alunos. A intensa cobertura midiática do caso (foram oito "posts") foi causada por uma série de elementos: o grande número de vítimas, o aspecto inédito do acontecimento (transferência de conflitos de bandos rivais dos bairros para o santuário escolar) e a exploração política do caso. Uma semana depois, o presidente da França anunciou medidas para lutar contra as gangues e para proteger o espaço sagrado das escolas.

Um segundo acontecimento marcou o noticiário do semestre estudado: a agressão de uma professora por um aluno armado com uma faca, em 15 de maio de 2009. Foi um caso grave, mas não o primeiro nem o último do ano. Em janeiro, um aluno agredira o seu professor com uma tesoura, um jovem ferira seu colega com uma faca, um aluno dera uma punhalada num diretor. Em março, um estudante do ensino médio recebera uma tesourada num olho, um aluno do ensino fundamental agredira dois colegas com uma lâmina, um adolescente levara uma facada na saída da escola. Em abril, uma aluna fora molestada sexualmente. No começo de maio, um aluno fora atacado com uma chave de fenda. No fim de maio, registraram-se os casos de um aluno agredido com um martelo e de um professor ameaçado por um estudante com uma faca. Em junho, dois alunos foram esfaqueados. Dois meses depois da invasão em Gagny e três semanas antes das eleições européias, esse caso foi muito explorado politicamente com grande repercussão na mídia. O ministro da Educação anunciou a instalação de detectores de metal nas escolas, revista de alunos na estrada e a criação de uma força policial destinada a agir rapidamente em caso de violência nos pátios escolares.

Esses acontecimentos provocaram dois comunicados do governo sobre a questão da segurança cujo impacto eleitoral é bem conhecido. Isso repercutiu nos "posts" do site de informação estudado. Foi em torno de 19 de março, por um lado, e depois de 22 de maio, por outro lado, que vários "posts" foram além da simples reportagem sobre os casos de violência escolar e destacaram as declarações políticas e as decisões governamentais nas proximidades de uma eleição européia (6 de junho de 2009) que estava longe de despertar o interesse dos eleitores. Passada a eleição, a efervescência da mídia sobre o assunto estancou. Muitos observadores denunciaram, então, a exploração eleitoralista dos casos de violência escolar, inclusive no Post.fr de 25 de maio de 2009: "Sarkozy relança o golpe da insegurança às vésperas das eleições européias?".

\section{Considerações finais}

Para concluir, voltando ao tema conhecimento e comunicação, vale relatar as consequências de um furo de reportagem sobre a dinâmica da contabilidade oficial dos casos de violência escolar estabelecida pelo Ministério da Educação.

O contexto: os primeiros casos graves de violência escolar foram abordados pela mídia no começo dos anos 1980. Mas foi durante a década de 1990 que as denúncias desses casos ganharam importância tanto na mídia quanto na sociedade. Primeiramente porque os próprios estudantes começaram a reclamar segurança nas escolas. Em seguida, as instituições escolares, por muito tempo mudas em relação ao assunto, não hesitaram mais em denunciar a violência 
escolar. Enfim, os políticos de esquerda, assim como os de direita, transformaram o problema em preocupação de campanha eleitoral.

Assim, no começo dos anos 2000, o Ministério da Educação começou um censo da violência escolar com o objetivo de, a partir da análise dos fatos, cada instituição adotar medidas preventivas. Cada escola indicou os casos graves de que fora palco a fim de que fosse estabelecida uma fotografia nacional do fenômeno. Os resultados globais foram publicados e analisados em Notes d'information, uma edição do Ministério da Educação. O volume de 2004, com base nos dados de 2002-2003, revela alguns limites da pesquisa: a subestimação, por um lado, das pequenas incivilidades diárias e, por outro lado, a superestimação dos casos graves, assim como a irregularidade nas declarações de cada estabelecimento, alguns simplesmente deixando de informar casos extremamente graves.

O furo: essa lógica de devolução dos resultados acabou depois de um furo de reportagem dado por uma revista de circulação nacional. Le Point (2006), no retorno às aulas de 2006, enquanto os dados oficiais sobre a violência escolar do Ministério da Educação limitavam-se a um tratamento estatístico (evolução e classificação dos casos), obteve da Justiça o direito, contra a vontade do Estado, de publicar o número total de casos de violência escolar em cada estabelecimento. Nem é preciso dizer que os pais caíram em cima dos resultados para conferir se os seus filhos estavam em segurança ou não. Havia problemas na operação.

$\mathrm{O}$ autor da reportagem reconhecia que os dados disponíveis eram enviesados (ou até mesmos falsos), mas justificava o seu "furo de reportagem" destacando a importância de quebrar o tabu relativo à publicação dos dados escolares. Afinal, sustentava, o contribuinte tinha o direito de conhecer esses números. Na capa, a revista anunciava: "Violência Escolar: exclusivo pela primeira vez na França a relação dos liceus e colégios mais perigosos".

No seu site, a revista dizia: "Le Point conseguiu obter os dados secretos da violência em todos os liceus e colégios públicos franceses e publica a lista dos estabelecimentos mais perigosos", uma reportagem exclusiva". Não se trata de modo algum de uma lógica de conhecimento. Outro problema desse furo consistiu em que as escolas que responderam francamente ao Ministério da Educação se sentiram caindo numa armadilha, enquanto que aquelas que não responderam, seja para protestar contra a política do governo ou por outra razão, acabaram por ser favorecidas. Assim, dois colégios da Academia de Montpellier ganharam lugar no podium dos três mais perigosos da França para surpresa do reitor da Academia e também de diversos observadores.

As consequências: elas foram imediatas. As escolas atingidas pararam de enviar seus dados de violência, invalidando qualquer tentativa de contabilizar e analisar os fatos. O Ministério da Educação destaca em sua Nota d'information, $\mathrm{n}^{\mathrm{o}} 20$, de dezembro de 2006, que "as interpretações dos critérios podem evidentemente variar de acordo com os lugares" e que "as comparações entre estabelecimentos", assim como os rankings da violência, não fazem sentido (Houllé, 2006). Mas o mal estava feito. Foi preciso mudar o método de observação e de avaliação da violência escolar. No retorno às aulas em 2007, os dados tratavam de mil estabelecimentos em vez dos seis mil anteriores.

Mas, sobretudo, o Ministério da Educação conseguiu fazer do novo "barômetro" um instrumento de pesquisa estatística legitimado pelo Centro Nacional de Informação Estatística (CNIS). Daí em diante "as respostas dos estabelecimentos são secretas e só podem ser utilizadas para fins estatísticos, não sendo permitida qualquer comparação entre escolas (Laib, 2008, p. 2).

Em resumo, entre a tentação dos políticos de instrumentalizar os casos de violência escolar e a vontade da mídia de explorá-los, o estudo da violência nos estabelecimentos escolares ainda não alcançou a serenidade.

Assim como na relação Ciência/Comunicação², a relação Educação/Comunicação dá espaço facilmente para considerações sociológicas. Afinal de contas, o ato comunicativo permeia totalmente a realidade social e age tanto sobre o campo da produção quanto sobre a transmissão dos conhecimentos ॠFAMECOS

\section{NOTAS}

* Este texto foi produzido a partir de seminário, "Imaginário, conhecimento e comunicação", ministrado no Programa de Pós-Graduação em Comunicação da Famecos/PUCRS, em setembro de 2009. Tradução de Juremir Machado da Silva.

1 Laurens, Jean-Paul. “A violência escolar, entre mídia e realidade", in Revista Famecos, $n^{\circ}$ 30, abril de 2006.

2 Laurens, Jean-Paul. "Sciences et communication: quelques considérations sociologiques", in Logos, $\mathrm{n}^{\mathrm{o}} 30,2009$, http://www.logos.uerj.br

\section{REFERÊNCIAS}

AUGER, Nathalie. La relation médias/société en question: un cas de violence scolaire dans une banlieue de Perpignan. In: Diversité, 2006.

BARTHÉLÉMY, Fabrice. Journalistes Enseignants: concurrence ou interaction? Paris: l'Harmattan, 2001.

BOURDIEU, Pierre; PASSERON, Jean-Claude. Les héritiers: les étudiants et la culture. Paris: Minuit, 1966. 
DARMAME, Mohammed. Les violences en milieu scolaire vues par la télévision. In: FRÉMONT, Pierre; BÉVORT, Evelyne. Médias, violence et éducation: l'école face aux discours sur la violence tenus dans les médias. Actes de l'Université de Caen, 5 a 8 de julho de 1999. Paris: CNDP-Clemi, 2001, p. 73-86.

FELOUZIS, Georges. Interactions en classe et réussite scolaire", una analyse des différences fillesgarçons". In: Revue Française de Sociologie, 1993. Le Collège au quotidien. Paris, Puf, 1994.

FRIEDMANN, Georges. Enseignement et culture de masse. In: Communication, $\mathrm{n}^{\mathrm{o}} 1$ 1, 1961; “L'école et les communications de masse, opinions, documents, débats", in Communication, $\mathrm{n}^{\mathrm{o}} 2$, 1963.

. L'école parallèle, Le Monde, 7, 8, 11 e 12 de janeiro de 1966.

. L'école parallèle, éduquer le consommateur, Le Monde, 11 de janeiro de 1966, p. 10.

HOULLÉ, Rodolph. Les actes de violence recensés par Signa en 2005-2006. In: Notes d'information, $\mathrm{n}^{\circ}$ 30. Direção de Avaliação, da Perspectiva e da Performance. Ministério da Educação Nacional, 2006.

JACQUINOT-DELAUNAY, Geneviève. Les sciences de l'éducation et de la communication en dialogue: à propos des médias et des technologies éducatives. In: Année sociologique, 2001, p. 293.

LAIIB, Nadine. Les actes de violence recensés par Sivis dans les établissements publics du second degré en 2007-2008. In: Note d'information, n 34, Direção de Avaliação, da Perspectiva e da Performance. Ministério da Educação Nacional, 2008.

. Nouveau système d'information sur la violence. In: Notes d'information, $\mathrm{n}^{\mathrm{o}} 34$. "Les actes de violence recensés par Sivis dans les établissements publics du second degré en 2007-2008. Note d'information, $n^{\circ}$ 34, Direção de Avaliação, da Perspectiva e da Performance. Ministério da Educação Nacional, 2008, p. 2.

LAURENS, Jean-Paul. A violência escolar, entre mídia e realidade. In: Revista Famecos, n 30, abril de 2006.

Sciences et communication: quelques considérations sociologiques. In: Logos, $\mathrm{n}^{\mathrm{o}} 30$, 2009, http://www.logos,uerj.br
La communication en classe. In: L'evaluation des eleves, de la fabrication de l'excellence à la régulation des aprentissages. Bruxelles: De Boeck, 1998.

MCLUHAN, Marshall. Guerre et paix dans le village planetaire. Paris: Laffont, 1970 (título original: War and peace in the global village, 1967).

. Message et massage, un inventaire des effets. Paris: Pauvert, 1968, p. 8 (título original: The médium is the massage: an inventory of effects, 1967.

La galaxie Gutenberg, la gênese de l'homme typographique. Paris: Mame, 1967 (título original: The Gutenberg galaxy: the making of typographic man, 1962).

Pour comprendre les médias: les prolongements technologiques de l'homme. Paris, Seuil, 1968, p. 8 (título original: Understanding media: the extensions of man, 1964).

. De l'oeil à oreille: la nouvelle galaxie. Paris: Denoël-Gonthier, 1977, p. 56-77 (título original: Processus and media, 1977).

PATY, Benjamin. La violence à l'école: étude d'une répresentation sociale comme facteur de stress des enseignants (tese de doutorado em psicologia social). Reims: 2004.

PERRENOUD, Philippe. Regards sociologiques sur la communication en classe. In: Métier d'éléve et sens du travail scolaire. Paris: Esf, 1994;

PORCHER, Louis. Télévision, culture, éducation. Paris: Colin, 1994.

. Les médias entre éducation et communication. Paris: Vuibert, 2009, p. 9.

SIROTA, Régine. L'école primaire au quotidien. Paris: Puf, 1988.

TARDY, Michel. Le professeur et les images. Paris: Puf, 1966.

Violence scolaire: exclusif pour la première fois en France le classement des lycées et collèges les plus dangereux. In: Le Point, $\mathrm{n}^{\mathrm{o}} 1772,31 \mathrm{de}$ agosto de 2006. 